Cite this article: Petraki V, Thomopoulos P, Kossioni AE. Factors affecting recent dental services utilization by an urban older population in Athens. Stoma Edu J. 2014; 1(1):48-51.

\section{FACTORS AFFECTING RECENT DENTAL SERVICES UTILZATION BY AN URBAN OLDER POPULATION IN ATHENS}

https://doi.org/10.25241/stomaeduj.2014.1(1).art.8

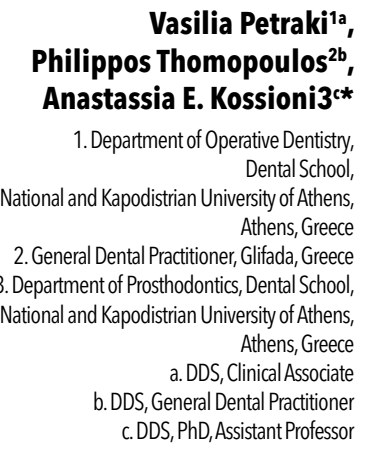

Received: 09 November 2013 Accepted: 21 January 2014

* Corresponding author:

Assistant Professor Anastassia E Kossioni, $\mathrm{DDS}, \mathrm{PhD}$

Department of Prosthodontics, Dental School, National and Kapodistrian University of Athens, Athens, Greece.

Thivon 2 Goudi, GR-11527Athens, Greece. Tel: +302107461212 , Fax: +302107461240 e-mail: akossion@dent.uoa.gr

\section{Abstract}

Introduction: The purpose of this study was to investigate the percentage of older people in an urban area visiting a dentist within the last 12 months and explore the particular effect of age, gender, education and dental status.

Methodology: Athens Dental School organized educational visits to a day center for older people in Athens, where the older visitors were interviewed and clinically examined. The patients' social and medical history and the time of the last dental visit were recorded. The clinical examination included the presence of natural teeth using appropriate portable equipment.

Results: A total of 77 older people, 53 females and 24 males, with a mean age of 73.8 years were recorded. Dental visits in the last 12 months were statistically significantly related to higher level of education (more than 6 years) $(p=0.037)$ and the presence of natural teeth $(p=0.014)$. More women had visited a dentist in the past 12 months but not to a statistically significant level. Fewer older old (aged 85 years and over) had recently visited a dentist but not statistically significantly.

Conclusion: The findings in the present study are in accordance to previous investigations in community-dwelling older adults indicating the importance of education and natural teeth in the utilization of dental services.

Key words: elderly, gender, edentulism, education, dental service utilization

\section{Introduction}

During the last decades the number of older people has continuously grown, as a result of increased life expectancy and low fertility rates (1). By the year 2050, the persons aged 60 years and over will be almost two billion world-wide and the large majority of them (80\%) will live in developing countries (2). The oldest old age group ( 80 years and over) is the most rapidly increasing proportion of the population, and is expected to increase from $0.5 \%$ in 1950 to $4.3 \%$ by 2050 (2). This demographic change will put significant strains on social security systems, including provision of general and oral health care.

More older people in the developed countries tend to maintain their natural dentition but the rates of oral disease, such as tooth loss, periodontal diseases, dental caries, xerostomia and oral cancer are still high (3-5).

The use of dental services has been investigated in relation to many factors, such as age, gender, dental status, ethnicity, income, education, general health status, dental and medical insurance (6-9). Increasing age, lower education and compromised self-rated health have been related to lower use of dental services by older Europeans (10).

The purpose of this study was to investigate the percentage of older people in an urban area, visiting a dentist within last 12 months and to explore the particular effect of age, gender, education and dental status.

\section{Methods}

Gerodontology is a lecture-based course taught in the 8th semester of the undergraduate studies at the Athens Dental School. Within this course, the students visit 


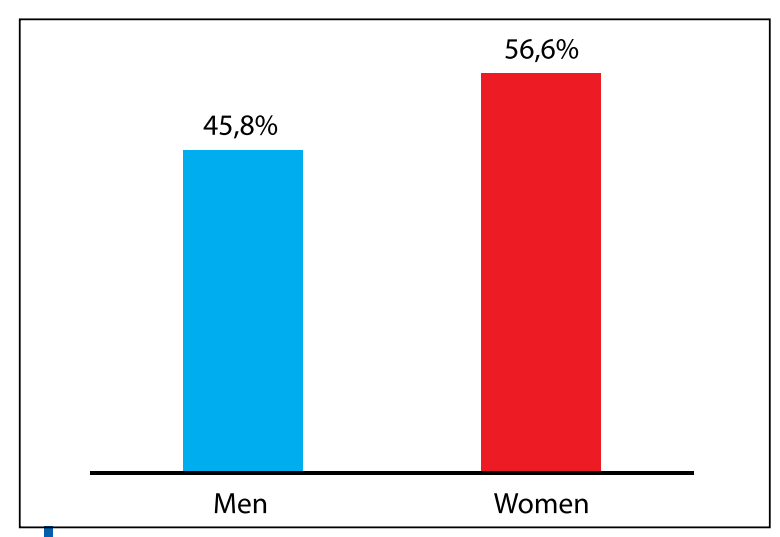

Figure 1. Dental visits by older adults in the past 12 months in relation to gender (\%), p>0.05

day centers for the elderly in the Metropolitan Athens area on a voluntary basis. In 2012, 34 students participated in these visits that included a thorough medical and dental history taking and an oral examination using portable equipment (11). The students and the members of the staff of the Dental School informed the older people about their current oral problems, provided oral hygiene instructions and advised on the proper use of dentures. One of the questions asked were if they had visited a dentist in the past 12 months.

The effect of gender (men, women), age $(<66$ years, 66-75 years, $76-85$ years and 85 years and over), education level ( $\leq 6$ years and $>6$ years) and dental status (dentate, edentulous), on visiting a dentist within the past 12 months were analyzed. The statistical analyses included descriptive statistics, chi-square tests and Fisher's Exact Tests. The level of statistical significance was set at $p \leq 0.05$.

\section{Results}

A total of 77 older people were examined, 53 women and 24 men, with a mean age of 73.8 years (SD: \pm 7.3 ). Their age ranged from 59 to 92 years. A total of $55.8 \%$ of them had attended fewer than 7 years of education and only $15.6 \%$ had completed tertiary education. A total of $15.6 \%$ were edentulous and $84.4 \%$ were dentate.

Almost half of the participants (53.3\%) had visited a dentist in the past 12 months. More women than men had recently visited a dentist (Figure 1) but this was not statistically significant (chi-square test, $p=0.528$ ). Fewer older old (85 years and over) had visited a dentist in the past year (Figure 2) but the statistical analysis did not record any statistical significance (chi-square test, $p=0.521$ ). Most of the people who had visited a dentist in the past 12 months had completed at least primary school education (6 years) (Figure 3) (Fishers Exact Test, $p=0.037)$. More dentate (60\%) than edentulous persons had visited a dentist in the last year (Figure 4) (chi-square test,

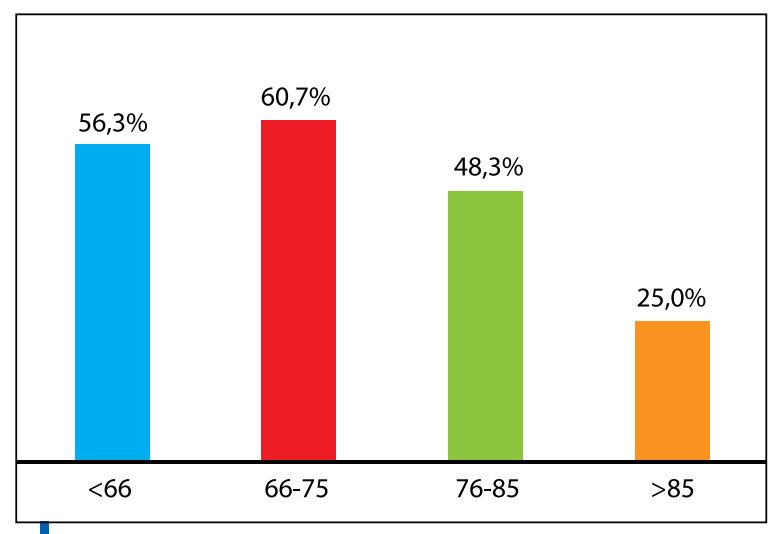

Figure 2. Dental visits by older adults in the past 12 months in relation to age (\%), p >0.05

$p=0.014)$. For $51 \%$ of the women and $42 \%$ of the men, prosthodontic treatment was the main reason for the last dental visit.

\section{Discussion}

This study offers an insight on the parameters that may affect dental consultation rates in an older urban European population.

More than half of the older participants had visited a dentist within the last 12 months. A previous study in a Greek population aged 5799 years has shown that $37 \%$ of the participants had visited a dentist in the past year (9). The higher percentage in the present study could be related to the specific sociodemographic characteristics of the sample (urban area, middleclass, motivation to be examined by a dentist in the day centre).

The two most important predictors for seeking dental care in the past 12 months were the higher level of education and having a natural dentition. On the other hand, sex and age did not significantly affect the time of the last dental visit.

The level of education is a significant predictor of dental utilization among older adults $(6,10)$. Previous surveys in Greece have also reported that, and low educational level was associated with lower use of dental services $(8,9)$. Similar were the findings in senior citizens in Canada (7).

A total of $60 \%$ of the dentate adults had visited a dentist in the last year, while this percentage decreased to approximately $17 \%$ in the edentulous ones. Similar were the findings in a previous study in 1751 older participants in Manitoba, Canada with a mean age of 76.2 years. The dental visits in the past 6 months in the dentate seniors were $36.2 \%$, compared to $13.5 \%$ in the edentulous ones (7). Furthermore, $46 \%$ percent of the edentulous Australians aged $55-74$ years had visited a dentist more than 5 years ago compared to $8 \%$ by the dentate ones (12).

Fewer men had visited a dentist in the past 12 months compared to women but not to a 


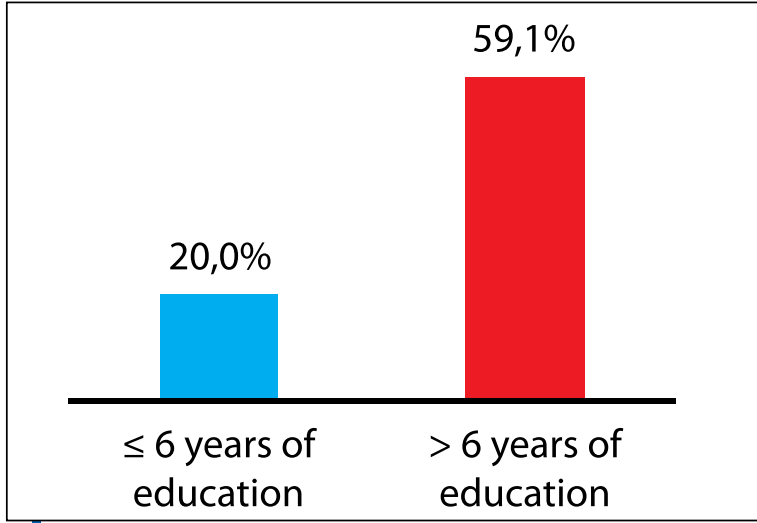

Figure 3. Dental visits by older adults in the past 12 months in relation to the level of education (\%), $p=0.037$

statistically significant level. In a previous study in Mexico City the male gender was associated with reduced dental service utilization (13). Similar were the findings in Australia (12).

Fewer older persons aged 85 years and over had recently visited a dentist but again this was not statistically significant. A previous study in a Greek population has shown a lower percentage of dental services' users in the past 12 months with increasing age (9). It may be suggested that the fewer recent dental visits by the older old is related to the higher rates of edentulism.

This study had some limitations. The sample size was small and included participants from a Metropolitan urban area with medium socio-economic status. Further research is needed to investigate utilization of dental services by the older population in more urban and rural areas in the country.

\section{Bibliography}

1. Kossioni AE. Is Europe prepared to meet the oral health needs of older people? Gerodontology.2012; 29(2):1230-1240.

2. United Nations. World Economic and Social Survey 2007. Development in an Ageing World. New York: Department of Economic and Social Affairs, United Nations; 2007.

3. Petersen PE, YamamotoTI. improving the oral health of older people: the approach of the WHO Global Oral Health Programme. Community Dent Oral Epidemiol. 2005; 33(2):81-92.

4. Petersen PE, Kandelman D, Arpin S, Ogawa H. Global oral health of older people - Call for public health action. Community Dent Health. 2010; 27(Suppl 2):257-267.

5. Kossioni AE. Current status and trends in oral health in the community-dwelling older adults. A global perspective. Oral Health Prev Dent. 2013; 11(4):331-340.

6. Kiyak HA, Reichmuth M. Barriers to and enablers of older adults' use of dental senvices. J DentEduc. 2005; 69(9):975-986.

7. Brothwell DJ, Jay M, Schönwetter DJ. Dental senvice utilization by independently dwelling older adults in Manitoba, Canada.J Can Dent Assoc. 2008; 74(2):161-161f.

8. Pavi E, Karampli E, Zavras D, Dardavesis T, Kyriopoulos J. Social determinants of dental health senvices utilisation of Greek adults. Community Dent Health. 2010; 27(3):145-150.

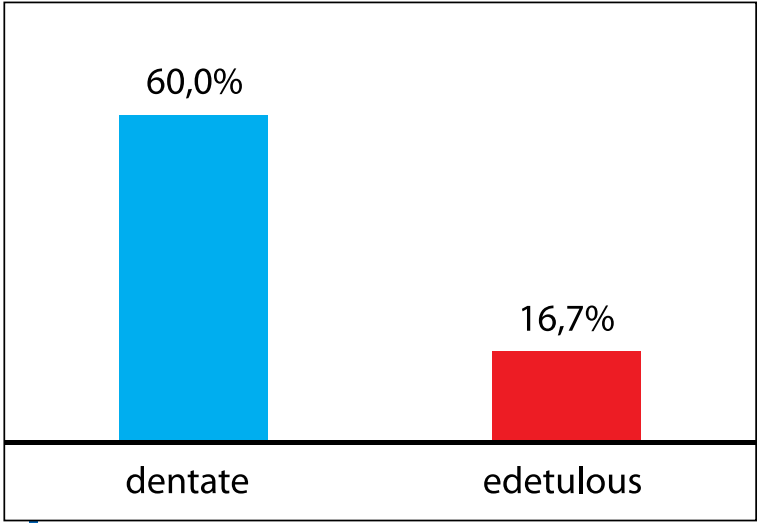

Figure 4. Dental visits by older adults in the past 12 months in relation to dental status (\%), $p=0.014$

\section{Conclusions}

Taking into account the limitations of this study, it may be concluded that the higher level of education and the dentate status are related to increased percentages of older people visiting a dentist in the past 12 months. The male gender and the older age were related to fewer visits but not to a statistically significant level.

\section{Acknowledgments}

The authors would like to thank the municipality of Zografos and the Director of the 1st day center for older people Mr. George Dimarides for the substantial assistance throughout the educational visits. Special thanks to the dental educators who participated in the program and Johnson and Johnson Hellas for the financial support.

9. Koletsi-Kounari H, Tzavara C, Tountas Y. Health-related lifestyle behaviours, socio-demographic characteristics and use of dental health services in Greek adults. Community Dent Health. 2011; 28(1):47-52.

10. Santos-Eggimann B, Junod J, Cornaz S. Health services utilisation in older Europeans. In: Borsch- Supan A, Brugiavini A, Jurges $\mathrm{H}$ et al. eds. Health, Ageing and Retirement in Europe. First Results from the Survey of Health, Ageing and Retirement in Europe. Mannheim: Mannheim Research Institute for the Economics of Aging (MEA); 2005:133-140.

11. Petraki V, Michael L, Gavela G, Kossioni AE. Dental status in older community-dwelling people in a day-center in Attica- A pilot study. Hellenic Stom Rev. 2012; 56(4):271-282.

12. Slade GD, Spencer AJ. Roberts-Thomson KF. Australia's dental generations. The National Survey of Adult Oral Health 2004-06. Canberra: Australian Institute of Health and Welfare (Dental Statistics and Research Series No. 34); 2007. AlHW cat. no. DEN 165.

13. Sánchez-García $S$, de la Fuente-Hernández J, Juárez-Cedillo $T$, Mendoza JM, Reyes-Morales H, Solórzano-Santos F, García-Peña C. Oral health service utilization by elderly beneficiaries of the Mexican Institute of Social Security in México city. BMC Health Serv Res. 2007;7:211. 
Vasilia Petraki

DDS, Clinical Associate, Department of Operative Dentistry, National and Kapodistrian University of Athens Dental School,

Athens, Greece

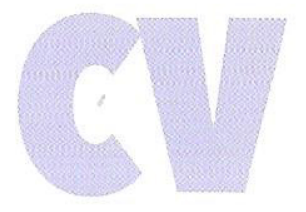

Dr. Vasilia Petraki was born in Rhodes and has recently (2013) graduated from the National and Kapodistrian University of Athens Dental School. She is currently clinical associate in Operative Dentistry at the same University. During her undergraduate dental studies she received several awards and distinctions for best academic performance.

She co-authored 3 publications in peer-reviewed scientific journals and participated in 8 oral presentations in national and international conferences. She was an active member of the European Dental

Students Association and one of her studies won the 1st prize at the 13th Athens dental students' conference. One of her main research interests is Gerodontology.

\section{What was the mean age of the patients?}

a. 23 yrs.

$\square$ b. 53 yrs.

c. 93 yrs.

d. $73.8 \mathrm{yrs}$.

What percent of the patients had attended fewer than 7 years of education?

a. $0 \%$

b. $100 \%$

c. $25 \%$

ad. $55.8 \%$

\section{What percent of the patients had completed tertiary education?}

a. $0 \%$

a b $100 \%$

c. $75 \%$

ad. $15.6 \%$

\section{What percent of the participants had visited a dentist in the past 12 months?}

a. $10 \%$

b. $25 \%$

$\square$ c. $53.3 \%$

ad. $75 \%$ 